\title{
An original approach to the mathematical concept of graph from braid crafts
}

\author{
Veronica Albanese ${ }^{1 \mathrm{a}}$, Natividad Adamuz-Povedano ${ }^{2}$, and Rafael Bracho-López ${ }^{2}$ \\ ${ }^{1}$ Universidad de Granada, Campus Cartuja s/n, Granada, 18071, Spain \\ ${ }^{2}$ Universidad de Córdoba, Adress, Córdoba, postcode, Spain
}

\begin{abstract}
In previous researches we found that a community of Argentinean artisans models its own practices of braiding using graphs. Inspired by these findings, we designed an educational activity to introduce the concept of graphs. The study of graphs helps students to develop combinatorial and systematic thinking as well as skills to model reality and abstract and generalize patterns from particular situations. The tasks proposed aim to construct the concept of graphs, then identify characteristics that allow some graphs to be models of braids and finally use them to invent more graphs for new braids. The activity performed in a secondary school teachers' educational course, had quite satisfactory results due to the number of braids invented and the small amount of mistakes made by the participants.
\end{abstract}

\section{Introduction}

This paper presents an educational approach to the mathematical concept of graph from an original perspective. In previous researches carried out in the field of Ethnomathematics [8 and 9], we found out that a community of Argentinean artisans models its own practices of braiding using some mathematical concepts [1] and in particular the concept of graph [1,3 and 12].

Inspired by these findings, we designed an educational activity to introduce the concept of direct graphs in secondary school. In this document we present a pilot experience, based on this activity, performed in a secondary school teacher's educational course that had quite satisfactory results due to the number of braids invented and the small amount of mistakes made by the participants.

\section{Significance of the study}

As the Principles and Standards for School Mathematics by the USA National Council of Teachers of Mathematics [11], the study of graphs is a component of the combinatorial topic that links various Mathematical branches as Geometry, Probability and Algebra.

\footnotetext{
${ }^{a}$ Corresponding author: author@e-mail.org
} 
Coriat, Sancho, Gonzalvo and Marín [7] point out the potentialities of graphs as a tool to model reality and to develop skills as learning how to think, facing new situations and handling information appropriately, while Kapur [10] indicates that the study of graphs makes the student develop the habit of examining all possibilities to list and find the best alternative, contributing to systemic thinking.

It has been demonstrated by the cognitive psychology research of Piaget (Piaget, \& Inhelder, 1951) that combinatorial schemes play an important role to develop formal operations in adolescents. Although Batanero, Godino and Navarro-Pelayo [5] and Batanero, Navarro-Pelayo, and Godino [6] underline that this learning process needs to be guided by teachers, who are not always prepared for it. That is one of the reasons why we implemented the first experience in teachers education.

\section{Objective}

The general objective of the study we present here is to Evaluate if the activity planned lets the participants achieve a good grasp of the concept of direct graph.

After describing the activity in the next section, we will specify more the objective.

\section{Methods}

We had the possibility to carry out the activity in a teacher's education course at the University of Buenos Aires. The course, in which this activity had been part of, was focused in Mathematical modelling connected to natural and social issues. It is relevant to mention that 12 of the 13 participants had not studied graph theory before.

\subsection{Description of the activity}

The activity consisted of three tasks. The first task aims to build the concept of graphs in a consensual way. The professor shows the participants how to create a simple craft braid of four threads (Albanese, Oliveras, \& Perales, 2012) and then they have to represent the process in a verbal and then graphical way, first individually and then in small groups. A pooling session is needed to share and compare the different representations and then to institutionalize the model that implies a direct graph (Figure 1).

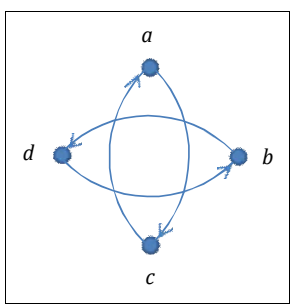

Fig. 1. Graph represented the simple braid of four threads for the first task.

During the second task the participants recognized the patterns that allow a graph to be a model of a braid working with three direct graphs modelling three braids of eight threads (Figure 2). 


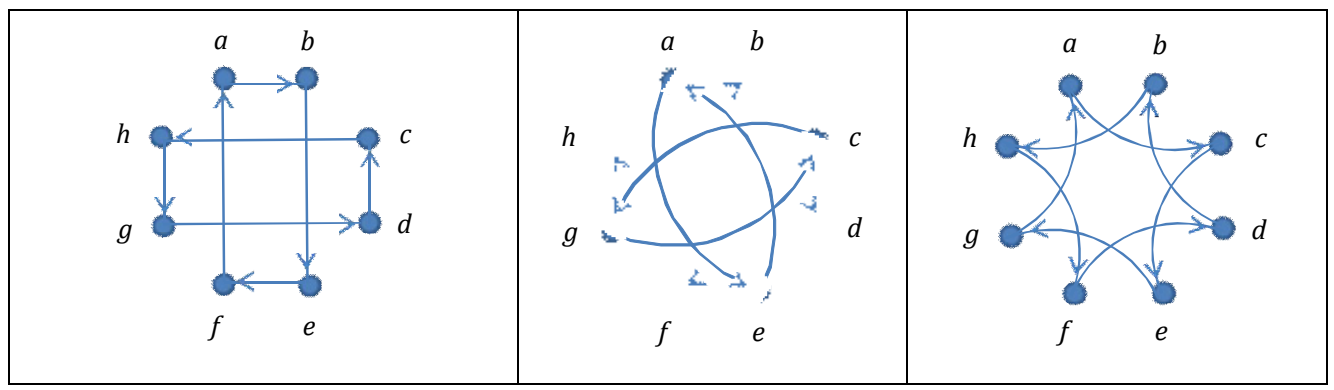

Fig. 2. Graphs represented the braids of eight threads for the second task.

These patterns can be translated in characteristics and properties of the paths that make up the graph itself.

Some of these patterns are:

1. Each vertex belongs to one and only one path.

2. The paths are closed so they are called circuits.

3. The circuits of a graph have the same number of vertices.

4. The graph is invariant by rotation of right angles.

5. The direction of the circuits is alternate (clockwise or anticlockwise).

Once identified most of these patterns, the third task consisted of inventing graphs modelling braids of sixteen threads that comply the patterns found in the previous task. The participants work directly with the graph model. The purpose is to generalize what they learn in the previous task using the inductive reasoning.

The graphs to invent should comply the patterns above. The key point to start with is to determine the possible number of vertices of each circuit. Patterns 1 and 3 imply that the number of vertices of each circuit -and so the number of circuit- in a graph of sixteen vertices should divide the number sixteen. Here we list the possibilities:

- 8 circuits, each of 2 vertices.

- 4 circuits, each of 4 vertices.

- 2 circuits, each of 8 vertices.

\subsection{The analysis}

We carried out a descriptive analysis of the productions of the participants, in particular here we present the results about the graphs proposed that represent some braids, which means the solutions of the third task described above. The qualitative analysis aims to classify these graphs in two categories, those complying the patterns required to represent a braid and those not complying these conditions.

\section{Some Results}

The analysis of the solutions of the third task, in particular the distribution of number of graphs proposed by participant (Figure 3), shows that two participants proposed up to six different graphs that allow the braiding, being three the most common, and only three participants proposed just one. The total number of graphs proposed were 40 . 


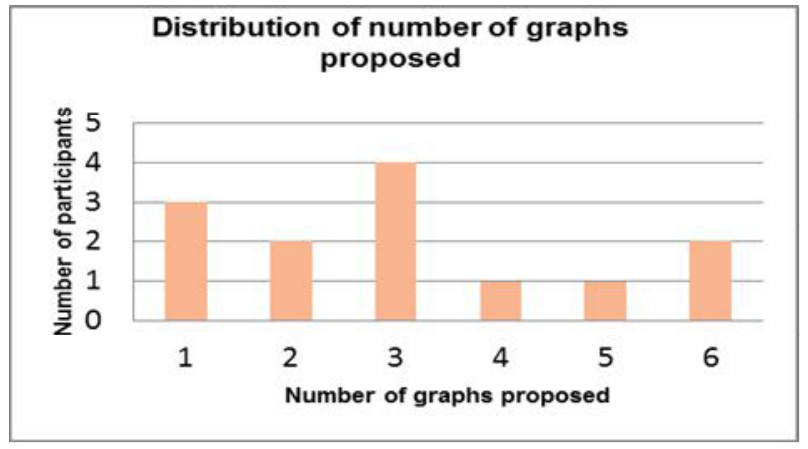

Fig. 3. Distribution of number of graphs proposed by participant.

In the next Figure 4 we show some of the graphs proposed by the participants that represent braids, in particular we choose one for each possible number of vertices in the circuit.

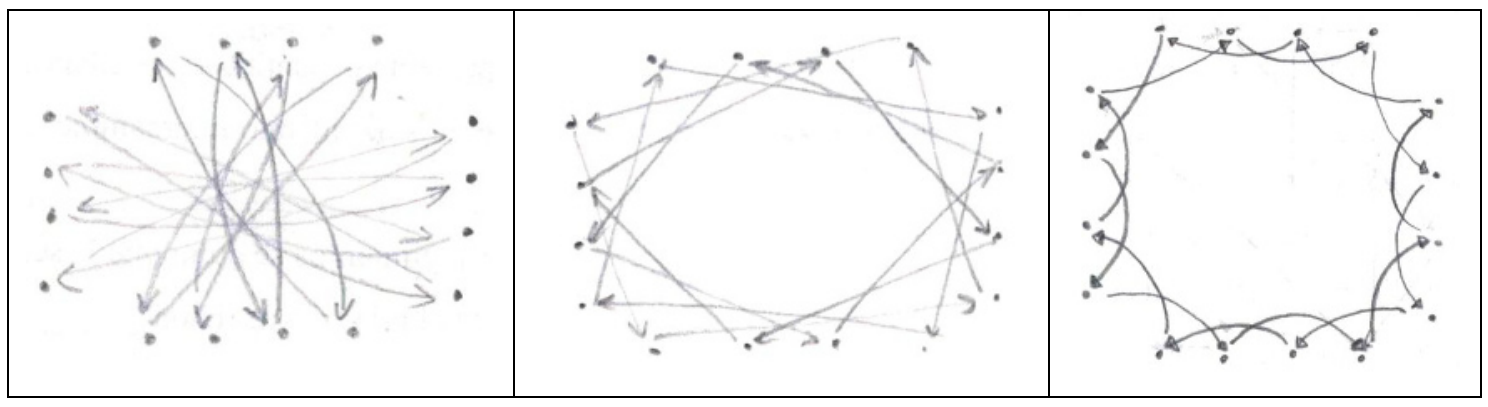

Fig. 4. Graphs proposed by the participants that represent braids.

Only two of the graphs proposed do not comply the conditions for making them a representation of a braid.

The two participants, who proposed them, realized respectively two and five graphs and just one of them does not represent a braid. In both cases the graphs comply all the patterns defined in section 4.1 except one: it is the pattern of the invariance by rotation of right angles.

\section{Conclusion}

These results are surprising and evidence the potentiality of this original approach to graphs. We consider that the constructivist and consensual way of introducing the concept first task- helps the participants to have an easier handling of the concept in problem solving -second and third tasks-. The participants could recognize the patterns and they performed a generalization process to apply them and proposed new graphs of a higher number of vertices.

The practical relation with braiding is a strong motivational factor.

As we point out in Section 2. Combinatorial issues -and especially graphs- help secondary school students to develop mathematical reasoning and real situation modelling. This activity is available to these students, as it does not require mathematically complex previous knowledge. An open research line is to implement the activity with secondary school students. 


\section{References}

1. Albanese, V., Etnomatemáticas en artesanías de trenzado y concepciones sobre las matemáticas en la formación docente. (Tesis doctoral). Universidad de Granada, Granada (2014)

2. Albanese, V., \& Perales, F. J., Pensar Matemáticamente: Una Visión Etnomatemática de la Práctica Artesanal Soguera. RELIME - Revista latinoamericana de investigación en matemática educativa, 17(3), 261-288 (2014)

3. Albanese, V., Oliveras, M. L., \& Perales, F. J., Etnomatemáticas en Artesanías de Trenzado: Aplicación de un Modelo Metodológico elaborado. Bolema, 28(48), 1-20. doi: 10.1590/1980-4415v28n48a0 (2014)

4. Albanese, V., Oliveras, M. L., \& Perales F. J., Modelización matemática del trenzado artesanal. Epsilon, 29 (81), 53-62 (2012)

5. Batanero, C., Godino, J. D., \& Navarro-Pelayo, V., Razonamiento combinatorio. Madrid: Editorial Sintesis (1994)

6. Batanero, C., Navarro-Pelayo, V., \& Godino, J. D., Effect of the implicit combinatorial model on combinatorial reasoning in secondary school pupils. Educational Studies in Mathematics, 32, 181-199 (1997)

7. Coriat, M., Sancho J. M., Gonzalvo, P., \& Marín, A., Nudos y nexos: redes en la escuela. Madrid: Editorial Sintesis (1989)

8. D'Ambrosio, U., Etnomatemática - Eslabón entre las tradiciones y la modernidad. México: Limusa (2008)

9. D'Ambrosio, U., Ethnomathematics and its place in the history and pedagogy of mathematics. For the learning of Mathematics, 5(1), 44-48 (1985)

10. Kapur, J. N., Combinatorial analysis and school mathematics. Educational Studies in Mathematics Education, 3(1), 111-127 (1970)

11. National Council of Teachers of Mathematics -NCTM-, Principios y Estándares para la Educación Matemática. Sevilla: Sociedad Andaluza de Educación Matemática Thales (2000)

12. Oliveras, M. L., \& Albanese, V., Etnomatemáticas en Artesanías de Trenzado: un modelo metodológico para investigación. Bolema, 26(44), 1295-1324. doi: 10.1590/S0103-636X2012000400010 (2012)

13. Inhelder, B., \& Piaget, J., De la lógica del niño a la lógica del adolescente. Barcelona: Paidós (1955) 